\title{
Perceptual Illusions and Military Realities
}

\section{RESULTS FROM A COMPUTER-GENERATED PERCEPTUAL DILEMMA}

\author{
S. PLOUS \\ Department of Psychology \\ Stanford University
}

Traditionally, the most common game-theoretic model of the nuclear arms race has been the Prisoner's Dilemma, in which participants are bound in conflict by the structure of the situation. Recent evidence suggests, however, that the nuclear arms race may be better approximated by a "Perceptual Dilemma" arising from discrepant perceptions of various outcome utilities. The present experiment compared the effects of two strategies, a matching strategy (called Status Quo) and a matching strategy preceded by unconditional cooperation (called Disarmament Initiatives), within the context of a Prisoner's Dilemma or a Perceptual Dilemma. Results indicated that: (a) the Status Quo strategy sustained competitive behavior, attitudes, and emotions in both the Prisoner's Dilemma and the Perceptual Dilemma; and (b) the Disarmament Initiatives strategy induced significantly more cooperation among subjects locked in a Perceptual Dilemma than those in nificanty morecose discussed in terms of political action and future research.

A great deal of past research on experimental gaming has used the iterated Prisoner's Dilemma as a model of the nuclear arms race between the superpowers (see Lindskold, 1978; Pilisuk et al., 1965; Pilisuk and Skolnick, 1968). Typically, the United States and the Soviet Union are seen as playing a $2 \times 2$ game, with four possible outcomes:

AUTHOR'S NOTE: I am grateful to Gary Bonitatibus, Cynthia L. Johnson, Lincoln E. Moses, Connie Roser, Jessica Utts, and Philip G. Zimbardo for their comments on an earlier draft. Please direct all correspondence to S. Plous, Department of Psychology, Stanford University, Stanford, CA 94305

JOURNAL OF CONFLICT RESOLUTION, Vol. 31 No. 1, March 1987 5-33

- 1987 Sage Publications, Inc. 
mutual disarmament, mutual armament, American armament and Soviet disarmament, or Soviet armament and American disarmament Disarmament corresponds to what has been traditionally labeled a "cooperative" choice, and armament corresponds to what has been called a "competitive" choice. Each side earns a payoff, whether positive or negative, depending upon the outcome of the given trial. The payoffs, usually represented on an interval scale, are intended to indicate some form of utility. They may or may not be equal for both players, and may or may not sum to zero. According to a Prisoner's Dilemma, the United States and the Soviet Union are always better off individually by arming, but if both superpowers arm, the collective outcome is lower in utility than if both countries disarm (see Table 1 for an example of a Prisoner's Dilemma).

This model has a certain historical appeal. For the first two decades following World War II, the United States was none too eager to relinquish its margin of nuclear superiority over the Soviet Union (Myrdal, 1982). Less clear is whether the arming responses of the Soviet Union reflected a preference for unilateral armament over mutual disarmament, or whether Soviet armament was merely intended to prevent the United States from incurring a unilateral advantage. In any event, the Prisoner's Dilemma is a plausible model for the early stages of the nuclear arms race.

By most estimates, however, the superpowers reached a state of strategic parity sometime early in the 1970s (see Russett, 1983:12), and the military value of additional nuclear weapons became dubious (Gaylor, 1982). Yet the superpowers continued to build more weapons, and with each new weapon system the cost and competition intensified. The probability of a nuclear war through accident or miscalculation may also have increased (La Rocque, 1981; Nunn and Warner, 1984; Perry, 1983).

Given the tremendous excess of nuclear weapons presently stockpiled by both superpowers, it is conceivable that for many political leaders the utility of mutual disarmament exceeded the utility of unilateral armament at some point in the 1970s (whether for reasons of military stability, economics, or otherwise). As Nikolai N. Inozemtsev, Director of the Soviet Institute of World Economy and International Relations, observed in 1982, "Political and military doctrines have been changed. This has been reflected in our internal life. There is a new determination to seek [arms] reductions"(Beres, 1982: 10). If so, the nuclear arms race might be characterized by what I have called a "Perceptual Dilemma"
TABLE 1

Prisoner's Dilemma Used in Experiment

\begin{tabular}{ccc}
\hline & B-Response & A-Response \\
\hline B-Response & 6.6 & $-7,7$ \\
A-Response & $7,-7$ & $-1,-1$ \\
\hline
\end{tabular}

NOTES: The first number in each cell denotes the outcome utility for a person play. ing the row position, and the second number denotes utility for a person playing the column position. Higher numbers indicate greater utility. These numbers are reproduced from the column utilities displayed in Table 2.

(Plous, 1985). Rather than sharing the same "matrix" of perceived utilities-as in a Prisoner's Dilemma-players locked in a Perceptual Dilemma hold discrepant perceptions of the payoff matrix, neither of which correspond to true outcome utilities. Three conditions underlie a Perceptual Dilemma: (1) both sides prefer mutual disarmament to all other outcomes; (2) both sides want above all to avoid disarming while the other side arms; and (3) both sides perceive the other side as wanting above all to arm while they disarm. If, for example, leaders of the United States and the Soviet Union were both to perceive the nuclear arms race according to the outcome utilities for row displayed in Table 2, when in fact the actual utilities were those found in Table 3, a Perceptual Dilemma would obtain.

Data on Soviet perceptions are unfortunately not available, but utility estimates from 32 United States senators clearly conform to the American half of a Perceptual Dilemma. In a previous study (Plous, 1985), members of the United States Senate were asked to indicate on a scale from -10 (worst possible) to +10 (best imaginable) what the consequences would be if: (a) the United States and the Soviet Union significantly reduced their nuclear arsenals, (b) only the United States made significant reductions, (c) only the Soviet Union made significant reductions, or (d) both countries maintained their present courses. Senators estimated the consequences of these four situations first for the United States and second, in an attempt to take the perspective of the Soviet leadership, for the Soviet Union. Rounded off to the nearest integer values, the average utility estimates were those found in Table 2.

Of course, it is possible that the senators were accurately reporting Soviet utilities and, intentionally or not, underemphasizing the utility of American unilateral armament; although the Prisoner's Dilemma was unsupported as a model of the nuclear arms race, it cannot be conclu- 
TABLE 2

Payoffs Presented to Subjects in a Perceptual Dilemma

\begin{tabular}{ccc}
\hline \hline & B-Response & A-Response \\
\hline B-Response & 8,6 & $-7,7$ \\
A-Response & $1,-7$ & $-5,-1$
\end{tabular}

NOTES: The payoff matrix above will lead to a perceptual dilemma when two parties simultaneously adopt the perspective of row. The first number in each cell denotes the outcome utility for a person playing the row position, and the second number denotes utility for a person playing the column position. Higher numbers indicate These numbers are rounded off from survey data given by 32 United States senators (see text).

TABLE 3

Payoffs Received by Subjects in a Perceptual Dilemma

\begin{tabular}{ccc}
\hline \hline & B-Response & A-Response \\
\hline B-Response & 8,8 & $-7,1$ \\
A-Response & $1,-7$ & $-5,-5$ \\
\hline
\end{tabular}

NOTES: The matrix above displays the actual payoffs received by subjects in a perceptual dilemma. The first number in each cell denotes the outcome utility for a person playing the row position, and the second number denotes utility for a person playing the column position. Higher numbers indicate greater utility.

sively ruled out. Moreover, the Prisoner's Dilemma produces competitive behaviors that are similar to those found in the nuclear arms race (Lindskold, 1978; Pilisuk, 1984; Pilisuk et al., 1965; Pilisuk and Rapoport, 1964; Pilisuk and Skolnick, 1968). Indeed, a central reason why the Prisoner's Dilemma has remained such a popular model of the nuclear arms race is the fierce competition it engenders.

How, then, are we to determine which model underlies the nuclear arms race? The litmus test may lie in disarmament initiatives. Unlike a Prisoner's Dilemma, in which participants are bound in conflict by the structure of the situation, a Perceptual Dilemma can be solved by demonstrating to each side that the other side desires mutual disarmament more than alternative outcomes. If participants in a Perceptual Dilemma are operating to maximize individual utility, they have every reason to reciprocate any disarmament initiatives made by the other party. Once both sides have discovered that mutual disarmament is individually and collectively optimal, the situation is transformed into a game of cooperation and the dilemma is solved. In contrast, mutual disarmament is not a stable solution to a Prisoner's Dilemma. In the case of a Prisoner's Dilemma, disarmament initiatives entail a great deal of risk, because either side can always defect from the "solution" to improve individual utility.

The present research was designed to compare the success of two strategies, Status Quo and Disarmament Initiatives, in resolving conflict once subjects have been locked into either a Perceptual Dilemma or a Prisoner's Dilemma. The Status Quo strategy, also known as tit-fortat or matching, mirrored whatever choice subjects made on the immediately previous trial (for empirical evidence supporting the reciprocal nature of the nuclear arms race, see Eckhardt and White, 1967; Gamson and Modigliani, 1971; Holsti et al., 1964; Sivard, 1983: 14; Ward, 1982). The Disarmament Initiatives strategy preceded matching with a fixed period of unconditional cooperation. To previde a particularly stringent test of how well these strategies succeeded in inducing cooperation, all subjects were informed before the game that the other person would probably attempt to outperform them, an expectation that often impedes conflict resolution (Hogan et al., 1973; Kelley and Stahelski, 1970; Kuhlman and Wimberley, 1976; Maki and McClintock, 1983; Messe and Sivacek, 1979; Miller and Holmes, 1975; Tedeschi et al., 1968). Two hypotheses were advanced: (a) under the Status Quo strategy, competitive attitudes, emotions, and behavior would be sustained in both the Prisoner's Dilemma and the Perceptual Dilemma; and (b) the Disarmament Initiatives strategy would produce significantly more cooperation among subjects locked in a Perceptual Dilemma than those in a Prisoner's Dilemma.

\section{METHOD}

Overview. Subjects were informed that they would be participating in a two-person experiment on decision making. They were told that a student from a rival university had been recruited to play the other role that day, and that the other person would interact with them via computer from a room down the hall. In reality, there was no other participant. Subjects played a 30-trial, 2-choice non-zero-sum game against one of two computerized strategies. After a 10-trial run of competition designed to lock subjects into conflict, the computer executed either: (a) the Status Quo strategy, which matched subjects' responses from 
immediately previous trials; or (b) the Disarmament Initiatives strategy, which disarmed unconditionally for 10 trials and matched thereafter. Depending upon their experimental condition, subjects were shown in advance either the payoff matrix in Table 1 (Prisoner's Dilemma) or the payoff matrix in Table 2 (Perceptual Dilemma; subjects slotted in the Row position), with the caveat that the computer might modify the payoffs somewhat according to experimental conditions. ${ }^{1}$ Subjects were instructed to monitor their trial-by-trial feedback to learn the exact consequences of each outcome. For the half who were presented with Table 2 (Perceptual Dilemma), the computer actually utilized the payoffs displayed in Table 3. Subjects who were presented with Table 1 (Prisoner's Dilemma) did indeed receive the payoffs contained in Table 1. To further simulate a competitive environment, all subjects were warned prior to the game that students from the rival university often attempted to obtain higher payoffs than those received by Stanford students. Once the game ended, subjects completed a large number of post-task measures and were invited to a group debriefing session. In sum, after the initial 10 trials of unconditional armament, the present study involved a $2 \times 2$ (Perceptual Dilemma/Prisoner's Dilemma $\times$ Status Quo/Disarmament Initiatives) factorial design, balanced with an equal number of males and females in each of the four conditions.

Subjects. In order to fulfill a course requirement, 42 students from the introductory psychology course at Stanford University participated. In addition, subjects had the opportunity to earn small monetary bonuses contingent upon task performance. Two subjects were excluded from the analysis, one for failing to comprehend the instructions and the other because of an apparatus failure, leaving a total of 10 subjects per condition. An equal number of males and females were assigned to each of the four experimental conditions, but because sex differences were not observed on any measures, data from both sexes were combined in subsequent analyses.

1. Because the external validity of experimentally induced dilemmas is dependen upon how well they approximate perceived outcome utilities in the nuclear arms race, the payoff matrices used during the experiment are based on responses from the United States Senate. The reasons for introducing the matrix as probable, rather than certain, are twofold: (1) perceived outcome utilties in the nuclear arms race are also uncertain, and (2) after the first trial of the experimental task, subjects in a Perceptual Dilemma could se that they were not receiving the exact payoffs contained in Table 2 . Of course, to the degree that hypothesized outcome utilities are so easily disconfirmed, the experimental situation differs from field settings.
Preliminary questionnaire. Several days or weeks prior to the experiment, subjects completed a survey on self-perceptions and perceptions of the United States and the Soviet Union. The survey, embedded in a packet of unrelated questionnaires, was administered as part of a survey packet routinely distributed in the introductory psychology course, thereby removing any obvious connection to the present research. Only students who had completed the questionniare were eligible to partiaipate in the experiment, so as to allow a comparison between prior survey responses and behavior during the experiment.

Included in the survey were two questions on how much the Soviet and American governments can be trusted, one question on which superpower has been more aggressive militarily since World War II, five questions on situational and dispositional attributions for the nuclear arms race, two questions on self-perceptions of trust, and a final section on utility estimates for different outcomes associated with the nuclear arms race. This final section asked students to indicate on a scale from -10 (worst possible) to +10 (best imaginable) what the consequences would be if: (a) the United States and the Soviet Union significantly reduced their nuclear arsenals, (b) only the United States made significant reductions, (c) only the Soviet Union made significant reductions, or (d) both countries maintained their present courses. Students estimated the consequences of these four situations first for the United States and second, in an attempt to take the perspective of a Soviet citizen, for the Soviet Union.

Procedure. As subjects arrived individually for the experiment, they saw a notice for "Stanford subjects," posted on the laboratory, which read

this experiment is unique in that it pairs Stanford students with Berkeley students as part of an ongoing research exchange program. Unfortunately, the extra coordination demanded by pairing two participants in two separate rooms occasionally leads to short delays. This has been taken into account, and you need not worry about the experiment ending on time.

To allow subjects enough time to read the sign, the experimenter appeared a few minutes late. The experimenter explained that he had just finished giving instructions to the other participant, and that he was now ready to deliver instructions to the subject. In actuality, there was no other participant. Subjects interacted with a computer preprogrammed to respond with a particular strategy. 
Subjects were escorted into a large laboratory containing four cubicles and were presented with the following taped instructions:

As you probably know, the field of computer networking has been growing in recent years. This experiment concerns the way in which joint decision making and social perceptions are affected when people interact through a computer link instead of in person. During the experiment, you will interact with another person via computer in a decision making task that has certain payoffs on each trial. payoff by yourself. Rather, the outcome will depend as much on what the other person does as on what you do. After the experiment, the computer will translate your total number of payoff points into money, based on how many positive points you earn and how many negative points you avoid. Any money that you earn will be paid to you in cash immediately after the experiment, and in no case will you lose any money. Your job, then, is to maximize the number of points you gain and minimize the number of points you lose.

The task works as follows. For each trial, the two choices open to both of you are to type an " $A$ " into the computer or to type a " $B$ " into the computer. This yields four possible outcomes for any one trial: you and the other person both choose " $A$ ", you and the other person both choose " $B$ ", you choose " $A$ " and the other person chooses " $B$ ", or you choose " $B$ " and the other person chooses " $A$ ". Every trial will begin by asking you to estimate, on a scale from 0 to 100 , what the chances are that the other person will choose an " $A$ " response. (Don't worry, the computer will explain how to make all ratings when they come up.) This rating is confidential; your estimate will not be disclosed to the other person, and you will never see the other person's estimates. Next, you and the other person will type in your choice of "A" or "B". Once both of you have typed in a choice, the computer will calculate your payoffs for that particular outcome. The payoffs awarded by the compute vary in different conditions of the experiment, but the table in front of you lists a close approximation of what they will be. After every trial, the computer will close approximation display the choices made by you and the other person, the exact payoffs for each of you on that trial, and the total number of points you and the other person have earned thus far.

Depending upon condition, subjects received a copy of either the payoffs shown in Table 1 (Prisoner's Dilemma) or the payoffs shown in Table 2 (Perceptual Dilemma, with subjects always slotted in the row position). At the conclusion of the experiment, all positive point totals were converted into cash at the rate of one penny per point. Although words that relate to competition, games, or the nuclear arms race did not appear during the experimental task, the reader may think of an " $A$ " response as "Armament" and a " $B$ " response as "Disarmament."

2. For clarity of exposition, armament will refer to what is customarily known as "competition" or "defection," and disarmament will refer to what is usually labeled as
After receiving the instructions, subjects completed a short quiz on the payoffs for each of the four outcomes contained in the matrix they were given. The purpose of this quiz was to ensure that subjects understood the system of payoffs. Subjects then answered three pretask stood the system of payoffs. Subjects then answered three pretask left to administer some final instructions to the other participant.

To stimulate a competitive atmosphere, subjects were given the following advice immediately preceding the experimental task:

Let me give you one last warning before you begin the experimental task. You might have already guessed this, but I'l just mention it to make sure the other merson doesn't take advantage of you. We have found that, when participating with person doesn't take advantage of you. We have found that when " $A$ " response. It looks Stanford students, students from Berkeley of like the reason for this has been to gain a higher payoff " $A$ ". That is not to say that payoff if you choose " $B$ " and the other person chooses "A". That is not to say that the person you are interacting with today will necessarily choose " $A$ ", but I thought you might want to know this background before you start. Okay, you have the go-ahead to begin.

The experimental task lasted for 30 trials. On the first 10 trials, the computer chose an " $A$ " response regardless of what the subject chose. computer chose an " $A$ " response regardless of what the subject chose.
These responses served the dual purpose of confirming the experimenter's warning and inducing an initial predisposition toward commenter's warning and inducing an initial predisposition towares petition. Thereafter, the computer executed one of two strategies: (a) Status Quo, in which the computer chose whatever response the subject selected on the previous trial; or (b) Disarmament Initiatives, in which the computer disarmed unconditionally during trials 11-20 and matched the subject's previous choices during the final 10 trials. Payoffs were as stated for subjects assigned to a Prisoner's Dilemma. For subjects exposed to a Perceptual Dilemma, the payoffs shown in the subjects exposed to a Peed following each trial were those contained in Table 3 , feedback statements following each trial were thosecone. Thus, the "other person" received the same set of payoffs as did the experimental subject.

On each trial, subjects made two responses. First, they were asked to predict what move the other person was likely to choose. The computer elicited this rating with the following instructions:

"cooperation." As in all game research, the heuristic value of these labels should not be "cooperation "As in all game research, the heuristic value of these labels should not be confused with external validity; the correspondence between experimental games and the nuclear arms race is itself an area of substantive research. 
On a scale from 0 to 100 , please estimate what you feel the chances are that the other subject will choose " $A$ " on the next trial. A rating of 100 would indicate that you are $100 \%$ confident that he or she will choose " $\mathrm{A}$ ", a rating of 0 would ind icate that you have $0 \%$ confidence he or she will choose " $A$ " (or $100 \%$ confidence that the othe subject will choose " $B$ "), and a rating of 50 would indicate that you feel the chances of an " $A$ " move and a " $B$ " move are exactly equal. In other words, any rating above 50 means that you feel the other person will probably choose " $A$ ", and any rating below 50 means that you feel he or she will probably choose "B". PLEASE ROUND OFF YOUR RATINGS TO THE NEAREST NUMBER ENDING IN O $(0,10,20,30,40,50,60,70,80,90$, or 100$)$. All estimates will be held in strict confidence - at no point during or after the experiment will you or the other person see each other's ratings.

Essentially, then, subjects used an 11-point scale (all multiples of 10 bounded by 0 and 100 ), yet the numbers intuitively corresponded to subjective probabilities (the perceived probability of an " $A$ " response) Next, subjects indicated their own move by typing either an " $A$ " or a " $B$ ". After a suitable delay to give the impression that the computer was waiting for a response from the other person, an announcement of each person's move and subsequent payoff appeared on the screen, along with the cumulative point totals for each side.

After every tenth trial, subjects were asked to rate their affect according to the following instructions:

On a scale from 1 to 9 , please rate how good you are feeling right now. A rating of 9 would indicate that you are feeling very, very good, a rating of 1 would indicate that you are not feeling good at all, and a rating of 5 would indicate that you are feeling exactly neutral, neither good nor bad.

They also did the same for ratings of anger and frustration. When combined with identical estimates that were elicited before the experimental task, these ratings afforded four repeated measures of three types of affect throughout the experimental period.

Following the thirtieth trial, subjects were told that they would be entering a new phase of the experiment in which "you will not be informed of the other person's choice of the payoffs you earn [but] the other person will continue to learn what you are choosing." They then estimated the probability that the "other person" would arm on the upcoming trial and selected " $A$ " or " $B$ " as before. In fact, although the subjects had no way of knowing it at the time, the new phase lasted for only one trial. The purpose of this special "thirty-first trial" was to assess how much subjects trusted the other person to disarm in the absence of verification.
At the conclusion of the experimental task, subjects answered several multiple-choice and short-answer questions concerning the task and the other person. They also responded to five open-ended questions: (a) If you had an opportunity to communicate directly with the other subject, what would you tell that person? (b) What strategy did you use during the experimental task? (c) Did the experimental task remind you of any other situations you've encountered or read about? (d) Have you ever heard of a Prisoner's Dilemma? If so, please try to define it as best you can; and (e) Please write any other questions or comments that you have regarding this experiment or the other person. Finally, each subject's data file was briefly reviewed, and the experimenter inquired about any atypical responses. These free responses provided a useful forum for the discussion of matters not directly addressed in the present design.

Once subjects had finished, the computer displayed one of two thankyou messages. If the cumulative point total was positive, the computer issued congratulations and displayed the bonus amount earned; subjects were then paid this amount in cash. If the cumulative point total was not positive, the computer announced that no bonus amount would be paid, but that subjects would still receive full credit for participating in the experiment

Debriefing was accomplished not only by revealing that the "other person" was fictitious, but by: (a) explaining the necessity of the deception; (b) stressing the amount of planning that went into making the deception believable, such as the computer delays after each trial that gave the impression another person was making ratings; and (c) mentioning that none of the other participants had detected any deception. Subjects were asked not to discuss the details of the experiment with anyone, they were invited to return for a copy of the results during the upcoming year, and they were thanked for their participation in the study.

\section{RESULTS}

Within both a Prisoner's Dilemma and a Perceptual Dilemma, the Status Quo strategy maintained highly competitive behavior. The Disarmament Initiatives strategy, although insufficient to resolve the conflict inherent in a Prisoner's Dilemma, produced significant increases in cooperation among subjects locked in a Perceptual Dilemma. 
Arming responses. Figure 1 contains the mean level of arming responses within 5-trial blocks. No significant differences among conditions were observed during the initial two blocks, in which the computer armed regardless of condition or subject behavior. At the end of the second trial block, subjects in both the Status Quo conditions and the Disarmament Initiatives conditions averaged 4.4 arming responses in the preceding 5 trials.

As hypothesized, subjects in the Status Quo conditions continued to arm at a high rate $(M=90 \%)$ throughout the remaining 20 trials, even though the computer was programed to reciprocate immediately any moves to disarm. Thus, once subjects had been competitively predisposed and had been confronted with an early run of arming responses, they persisted in arming-despite visual feedback announcing their point losses after each trial, despite the fact that the initial arming they encountered could have been explained as defensive rather than aggressive in nature, and despite the fact that subjects in a Perceptual Dilemma shared a preferred outcome (mutual disarmament) with their presumed adversary.

In the Disarmament Initiatives conditions, the computer unconditionally disarmed during the third and fourth trial blocks. By the end of the fourth block, the number of arming responses by subjects in a Prisoner's Dilemma had fallen to approximately half ( $M=48 \%$ ). Among subjects in a Prisoner's Dilemma, unconditional disarmament therefore produced more disarming responses in the fourth block $(M=2.4)$ than did the matching strategy of the Status Quo $(M=4.3)$, $t(18)=2.62, p<.01$, yet the disarmament was far from complete. Within the fourth block, seven of the ten subjects in the Disarmament Initiatives/Prisoner's Dilemma condition continued to arm while the computer disarmed.

In contrast, seven of the ten subjects in a Perceptual Dilemma responded to disarmament initiatives with disarmament on all five trials of the fourth block, and the average probability of arming responses for these ten subjects fell from $78 \%$ in the second block to $20 \%$ in the fourth block. Unconditional disarmament for subjects in a Perceptual Dilemma produced an average fourth-block arming rate significantly lower $(M=1.0)$ than the corresponding rate for subjects in a Prisoner's Dilemma $(M=2.4), t(18)=1.93, p<.05$.

More important, however, is what occurred in the final two blocks when the matching strategy was instated. For subjects in a Prisoner's Dilemma, periodic attempts at exploitation were met with reciprocal

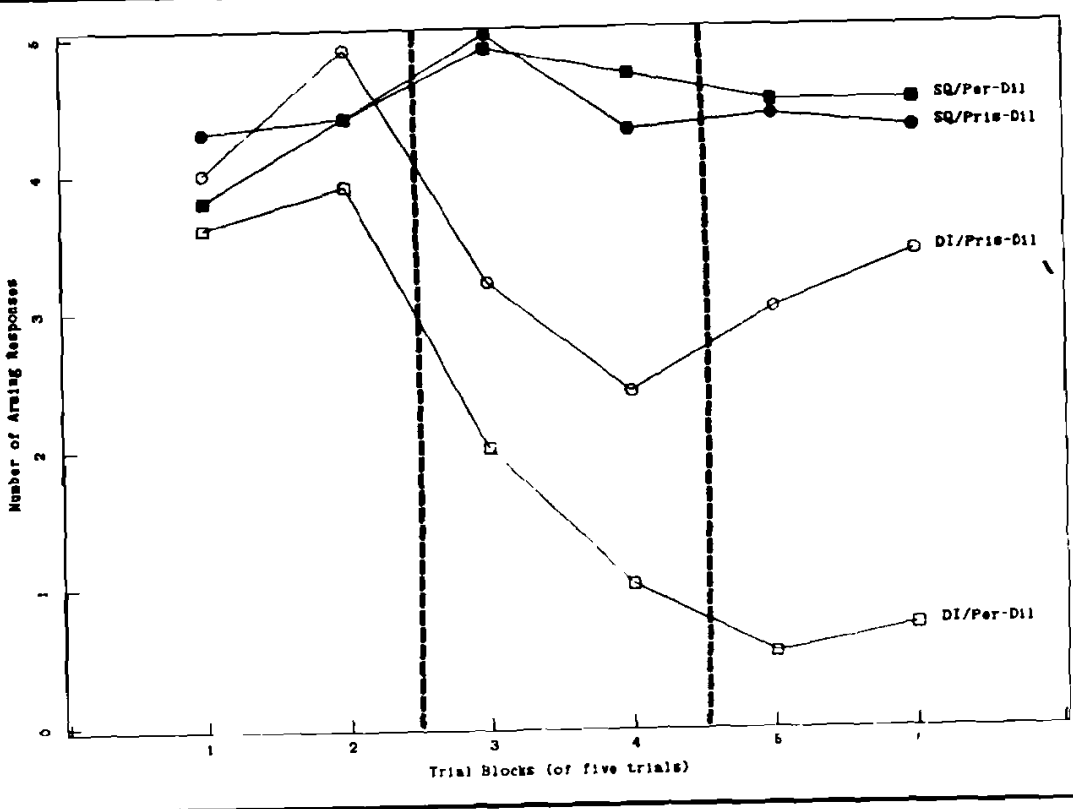

Figure 1: Number of Arming Responses by Experimental Condition

arming responses by the computer and led to a competitive spiral in several cases. Arming responses rose to $68 \%$ by the sixth block, not significantly different from subjects in the Status Quo/Prisoner's Dilemma condition $(M=86 \%), t(18)=1.14$, n.s., and apparently still rising. Subjects in Disarmament Initiatives/Perceptual Dilemma condition had little incentive to arm, however, and arming responses fell to a terminal rate of $12 \%$ in the final 10 trials. Of the 10 subjects in a Perceptual Dilemma who had been exposed to disarmament initiatives, only 1 continued to arm steadily throughout all 30 trials. When interviewed after the experiment, this subject explained her behavior as an attempt to maximize the difference between her earnings and those of the alleged Berkeley student. Because she did not view mutual disarmament as the most desirable outcome, then, her perceived utilities may be better approximated by a Prisoner's Dilemma than a Perceptual Dilemma.

Subjective probability estimates. As displayed in Figure 2, subjective probability estimates that the "other person" would arm closely resembled the results in Figure 1. By the end of the second trial block, 
subjects in all four conditions estimated an average probability of between $80 \%$ and $90 \%$ that the "other person" would arm on the following trial. For the remaining 20 trials, subjective probability estimates for subjects in the Status Quo conditions averaged $93 \%$. In the Disarmament Initiatives conditions, subjects showed a linear decline in average probability estimates during the third and fourth blocks (to a low of $22 \%$ ), followed by a sharp increase (to $61 \%$ in the final block) for subjects in a Prisoner's Dilemma and a nonsignificant increase (to 27\% in the final block) for subjects in a Perceptual Dilemma. Once the matching strategy had been instated after unconditional disarmament, subjects in a Prisoner's Dilemma (correctly) anticipated that the "other person" would choose armament, while subjects in a Perceptual $\mathrm{Di}$ lemma (correctly) expected the "other person" to continue disarming.

Trust. On a special "thirty-first trial," subjects were told that from then on only the other person would receive feedback concerning the choices made by each participant. By removing subjects' capability for verification, a belief that the "other person" would disarm (whether for humanitarian reasons or out of self-interest) became necessary for disarmament. Not surprisingly, 17 of 20 subjects in the Status Quo conditions armed on the thirty-first trial, with an average subjective probability estimate of $88 \%$ that the "other person" would arm. Of the ten subjects in the Disarmament Initiatives/Prisoner's Dilemma condition, nine also chose armament, averaging a $73 \%$ estimate that the "other person" would arm. In the Disarmament Initiatives/Perceptual Dilemma condition, however, nine out of ten subjects chose disarma$m e n t$, and the average probability estimate was $38 \%$ (the lone subject who chose armament is the individual mentioned previously who had armed throughout the 30-trial interaction; accordingly, her probability estimate was $100 \%$ ). The pattern that emerges is one in which subjects who received disarmament initiatives in the context of a Perceptual Dilemma trusted that their counterpart would disarm, so they themselves disarmed. Conversely, subjects in the other three conditions believed that the "other person" would arm, so they themselves armed. Disarmament initiatives produced trust (disarmament in the absence of verification) in the context of a Perceptual Dilemma, but not in the context of a Prisoner's Dilemma.

Affect. Subjects were asked to rate on a scale from 1 to 9 how good, how angry, and how frustrated they felt immediately prior to the 30-trial

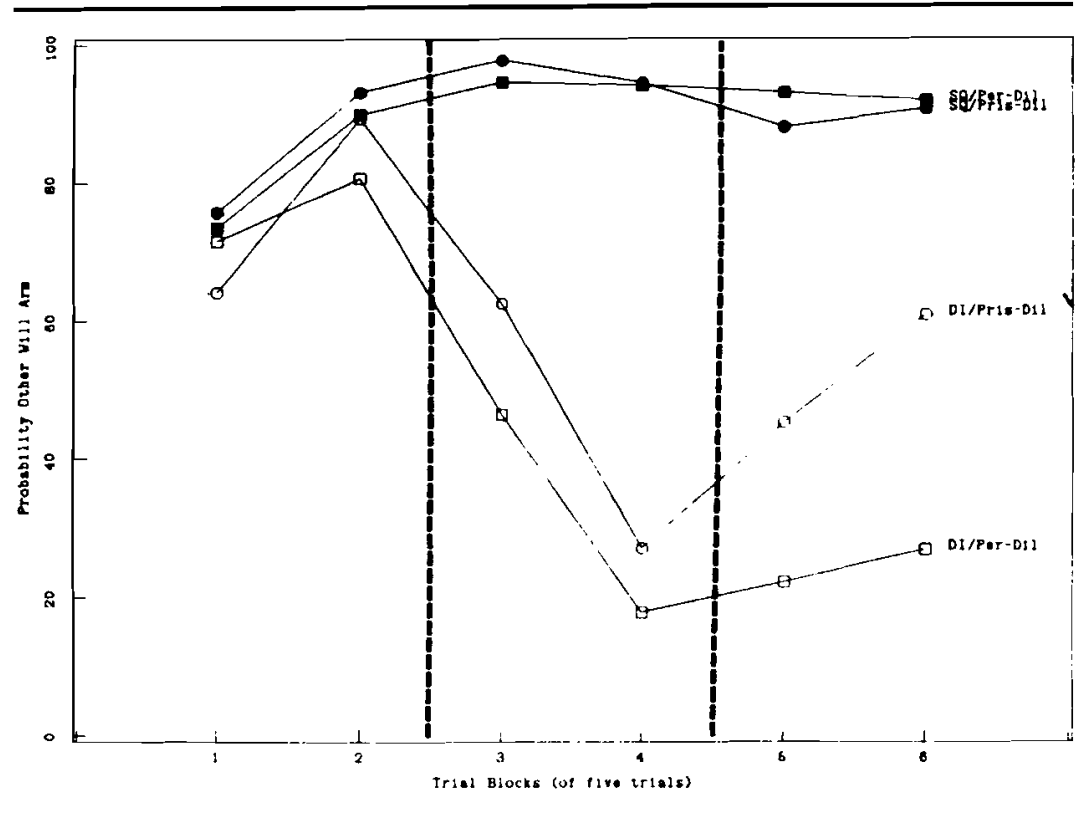

Figure 2: Subjective Probability Estimates That the "Other Person" Would Arm on the Next Trial

interaction, after the first 10 trials, after the second 10 trials, and after the final 10 trials. Because the three mood ratings were typically found to correlate between .50 and .70 , they were combined to form a composite measure of affect. ${ }^{3}$ Figure 3 depicts mean changes in affect for each of the four conditions.

As can be seen, mood in all four conditions declined during the initial 10 trials of unconditional armament $(M=-3.1$ scale points $), t(39)=4.62$, $p<.001$. Although subjects in the Status Quo/Prisoner's Dilemma condition rated their moods somewhat more positively $(M=-0.3$ averaged over time) than other Status Quo subjects $(M=-3.0)$, this trend was not significant, $t(18)=1.46$, n.s., nor were differences among conditions before the experimental interaction (all $M$ between -0.7 and 2.3), $F(3,36)=1.01$, n.s., or after the first 10 trials (all $M$ between -0.7 and $-3.1), F(3,36)=.45$, n.s. Following the decline in mood during the first

3. The composite was formed by subtracting the measures of anger and frustration from the rating of how good subjects were feeling. 


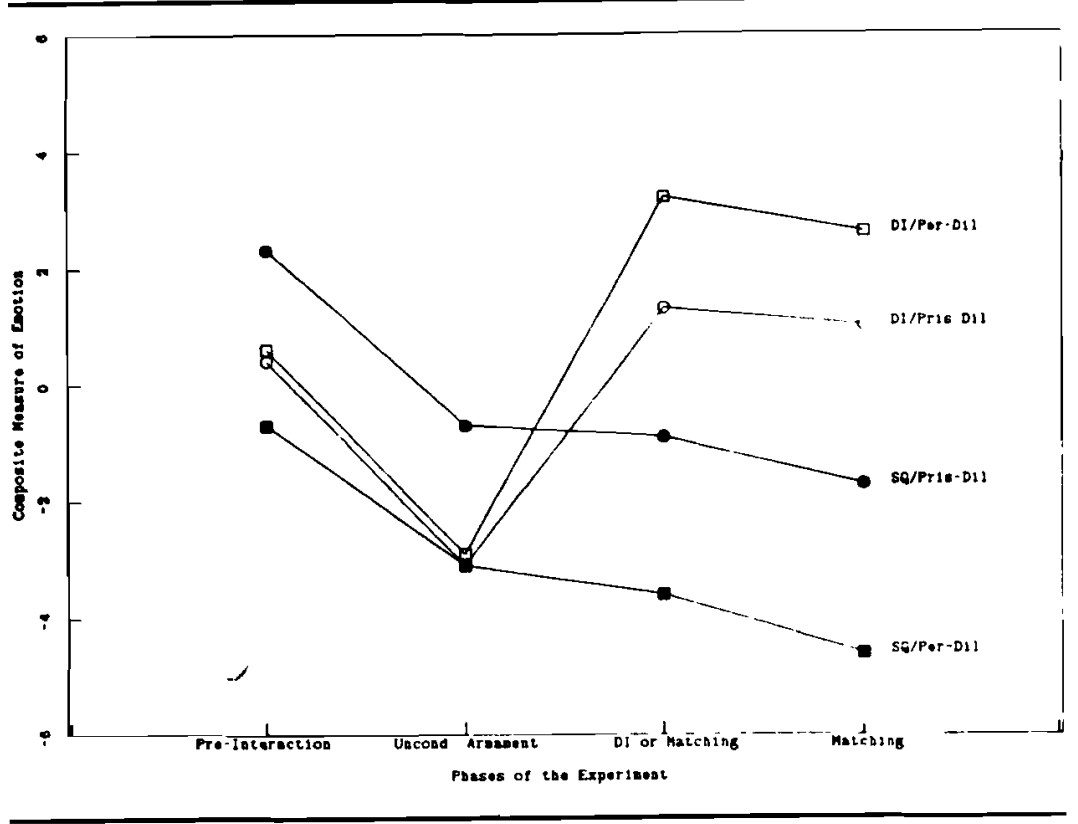

Figure 3: Changes in Composite Measure of Affect by Experimental Condition

10 trials, subjects in the Status Quo conditions tended to maintain or slightly intensify their negative feelings. Subjects who were exposed to disarmament initiatives, on the other hand, showed strong positive changes in self-rated affect $(M=5.3), t(19)=4.70, p<.001$. Indeed, mood ratings for these subjects were higher after having been exposed to disarmament initiatives $(M=2.3)$ than they were immediately before the 30-trial interaction began $(M=0.5), t(19)=2.27, p<.05$. Apparently, the experimental interaction was an emotional experience for many of the subjects, even though any overt connection to the nuclear arms race was removed and the stakes were relatively small.

Two additional bodies of evidence support the emotional quality of the experimental interaction: (a) correlations between mood ratings and certain postinteraction measures; and (b) spontaneous comments offered by several subjects. Pre- to postinteraction decrements in mood correlated highly with later estimates of the percentage of arming responses by the "other person," $r(39)=.60, p<.001$, ratings of how cooperative the "other person" turned out to be, $r(39)=-.59, p<.001$, whether or not the subject armed on the thirty-first trial, $r(39)=.54, p<$
.001 , the subjective likelihood that the "other person" would arm on the thirty-first trial, $r(39)=.48, p<.005$, and ratings of how responsive the "other person" was seen to be, $r(39)=-.38, p<.02$. After the experimental interaction, a number of subjects offered affect-laden comments about the "other person" and the interaction, including: "If I was in the same room with the other person I probably would have killed them [sic] by now," "I felt he was trying to make me mad, " and " $k$ became an ego battle after the first fifteen trials and I didn't particularly care to lose." Coupled with the pattern of results shown in Figure 3, these comments and correlations suggest that many of the emotional overtones inherent in the nuclear arms race were amply reproduced in the laboratory.

Generalization. Further support for the external validity of the laboratory situation can be found in postinteraction ratings subjects made concerning their general impressions of the alleged Berkeley student. Specifically, subjects who had received disarmament initiatives within the context of a Perceptual Dilemma evaluated the Berkeley student more favorably than did subjects in the other three conditions (as revealed by planned contrasts). Compared with other subjects, individuals in the Disarmament Initiatives/Perceptual Dilemma condition rated the "other person" as more honest, $(M=7.0$ versus 5.6$), F(1,36)=$ $7.24, p<.02$, more similar in outlook and behavior to themselves $(M=7.2$ versus 5.0$), F(1,36)=9.36, p<.005$, more desirable as a friend $(M=6.7$ versus 4.8$), F(1,36)=8.76, p<.01$, and more responsive $(M=4.8$ versus 2.6$), F(1,36)=4.97, p<.05$. Thus the effects of disarmament initiatives upon subjects locked in a Perceptual Dilemma strongly generalized to the domain of social perception.

Perceived versus actual control. In terms of actual control over the “other person's" behavior, subjects in the Status Quo conditions faced 10 trials of unconditional armament and 20 trials of response-contingent matching. Hence, they were able to influence what the "other person" chose on a total of 20 trials. In the Disarmament Initiatives conditions, subjects were exposed to 10 trials of unconditional armament, 10 trials of unconditional disarmament, and a final 10 trials of matching. Consequently, subjects in the Disarmament Initiatives conditions were able to influence the "other person" on only half as many trials as subjects in the Status Quo conditions.

In terms of perceived control, the results were just the opposite. Compared with subjects in the Disarmament Initiatives conditions, 
subjects in the Status Quo conditions indicated after the interaction that they had felt less control over the ultimate outcome $(M=2.9$ versus 4.9$)$, $F(1,36)=10.86, p<.005$, and less choice in their responses $(M=1.7$ versus 4.2), $F(1,36)=16.43, p<.001$. Whereas subjects in the Disarmament Initiatives conditions felt that they and the "other person" had wielded approximately the same amount of choice in response options ( $M=4.2$ for self and 4.5 for other), subjects in the Status Quo conditions perceived the "other person" as having had greater choice than they had in whether to arm or disarm $(M=1.7$ for self and 4.4 for other $), F(1,36)=$ $7.19, p<.02$. In general, the restriction of choice subjects perceived for themselves was strongly related to estimates of the percentage of arming responses made by the "other person," $r(39)=.61, p<.001$, yet perceived limitations in the "other person's" choices were not significantly correlated with subjects' estimates of the percentage of their own arming responses, $r(39)=.23$, n. s. Reminiscent of the nuclear arms race, subjects in the Status Quo conditions felt compelled to arm in response to the "other persons's" armament, but they did not perceive the continuation of their own armament as creating similar constraints for the "other person."

Overconfidence in misperceived strategies. After the experimental interaction, subjects were asked to read through a list of strategies and indicate the one strategy that came closest to describing the other person's behavior during the interaction. Of the 20 subjects who had received disarmament initiatives, 16 correctly identified that the "other person" had begun with armament and later switched to disarmament. When asked to indicate (on a scale from $0 \%$ to $100 \%$ ) how confident they were that they had accurately described the "other person's" strategy, these subjects averaged $68 \%$, a moderate degree of confidence by most standards (Fischhoff et al., 1977; Lichtenstein et al., 1982).

Of the 20 subjects in the Status Quo conditions, 15 subjects erroneously believed that the "other person's" strategy was to arm "pretty much regardless" of what they did, 2 subjects correctly identified that the "other person" had begun with armament and later matched what they had chosen on previous trials, and 3 subjects incorrectly identified other strategies that they believed the "other person" had executed. Because the majority of subjects in the Status Quo conditions had armed throughout the period in which matching was introduced-and therefore had no logical basis for discriminating between 30 trials of unconditional armament versus 10 trials of unconditional armament followed by 20 trials of response-contingent matching-it is particularly noteworthy that three-fourths of the subjects felt as though there was nothing they could do to terminate the "other person's" armament. Nor were these misperceptions lightly held. The mean confidence rating was 95\% for subjects who believed that the "other person" had armed more or less unconditionally, compared with $70 \%$ for the two subjects who had correctly identified the "other person's" strategy and $83 \%$ for the three remaining subjects. On the whole, subjects in the Status Quo conditions strongly believed that the "other person" had pursued a course of unrelenting armament.

Personality and attitudinal correlates of armament. The relationship between armament and certain relevant personality or attitudinal variables was assessed using data from a survey administered well in advance of the experimental session. The purpose of this analysis was to see, for example, whether subjects who viewed themselves as trusting, or who viewed mutual disarmament as valuable, would be less likely to choose armament than subjects who did not hold such views. Among other things, the survey asked respondents to rate the following four personality and attitude dimensions on a scale from 1 to 9: (a) their general willingness to trust compared with most people; (b) their general willingness to trust compared with their willingness a year earlier; (c) the degree to which the Soviet government can be trusted; and (d) hypothetically, the degree to which respondents would want to end the nuclear arms race if they were elected president of the United States. Subjects also completed American and Soviet utility estimates for the same four arms-race outcomes as the computer had simulated, to see if, for example, subjects who attached the highest utility to mutual disarmament or the lowest utility to mutual armament would be less likely to perpetuate mutual armament in the experimental interaction. These eight utility estimates and the four personality/attitude measures were correlated with eight indices related to armament: (a) whether or not subjects armed on the first trial (before encountering armament from the "other person"); (b) subjective probability estimates that the "other person" would arm on the first trial (also before any feedback); (c) the number of arming responses made during the first trial block; (d) average subjective probability estimates that the "other person" would arm during the first trial block; (e) the total number of arming responses; (f) average subjective probability estimates that the "other person" would arm throughout all 30 trials; $(\mathrm{g}$ ) whether or not subjects armed on the special 
thirty-first trial; and (h) subjective probability estimates that the "other person" would arm on the thirty-first trial.

The correlations are shown in Table 4. Only the first-block indices of armament were significantly correlated with personality and attitude measures. Total arming responses during the first five trials were negatively related to the degree subjects felt they could trust the Soviet government, $r(39)=-.37, p<.05$, their estimates of the American utility of mutual disarmament, $r(39)=-.30, p<.05$, and their estimates of the Soviet utility of mutual disarmament, $r(39)=-.31, p<.05$. First-block arming responses were also positively associated with estimates of the Soviet utility of mutual armament, $r(39)=.35, p<.05$. Average probability estimates that the "other person"would arm during the first trial block were correlated with estimates of both the American utility of unilateral armament, $r(39)=.39, p<.05$, and the Soviet utility of unilateral armament, $r(39)=.39, p<.05$. Arming responses and expectations on the first trial (in the absence of feedback), as well as behavior after subjects had been exposed to unconditional armament, were unrelated to personality and attitude measures.

Although the modest size and small number of significant correlations in Table 4 warrant caution in interpretation-among 96 correlations, five would be expected to reach the .05 level of significance by chance alone-the results follow a consistent pattern. Only during the early trials of the experimental interaction, when subjects first encountered an arming counterpart, were the reciprocation and expectation of armament related to prior utility estimates for arms-race outcomes. Prior beliefs were unrelated to first-trial behavior (in the absence of feedback), and they quickly became immaterial once situational constraints took hold.

\section{DISCUSSION}

Hypotheses. This study was designed to test two hypotheses: (a) that the Status Quo strategy would sustain competitive behavior, attitudes, and emotions in both the Prisoner's Dilemma and the Perceptual Dilemma; and (b) that the Disarmament Initiatives strategy would foster significantly more cooperation among subjects locked in a Perceptual Dilemma than those in a Prisoner's Dilemma. Both of these hypotheses were strongly supported. After an initial run of arming responses by what appeared to be an aggressive adversary, subjects in

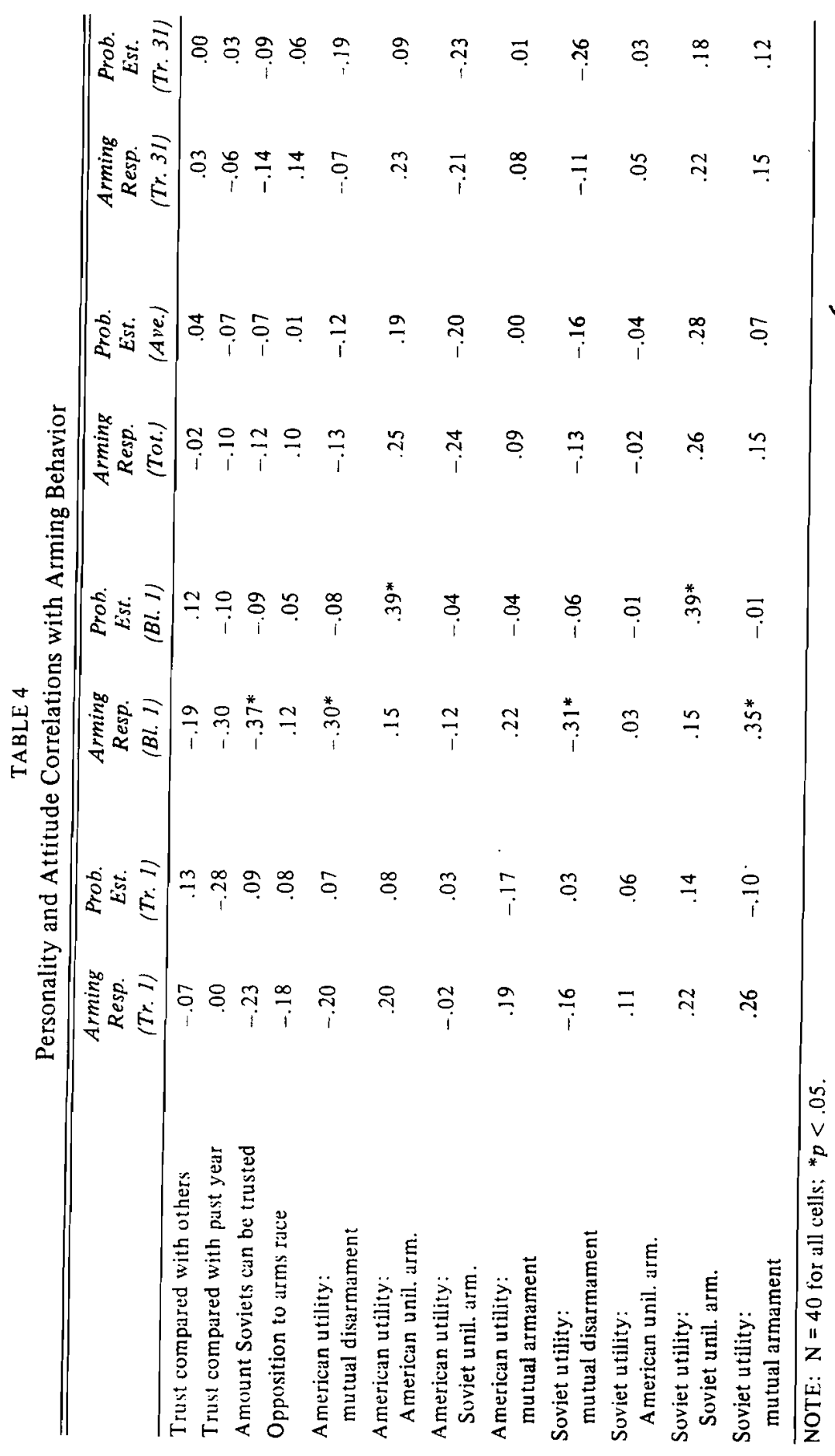


the Status Quo conditions continued to arm at very high rates for the remainder of the experimental interaction, even though any moves to disarm would have been reciprocated immediately. They also continued to believe that the "other person" was intent on arming, and they displayed significant declines in self-rated mood during the course of the interaction.

For subjects exposed to disarmament initiatives after the preliminary round of competition, the story was much different. Although the terminal rate of arming responses for subjects in a Prisoner's Dilemma did not differ from rates found in the Status Quo conditions, arming responses among subjects in a Perceptual Dilemma were, with the exception of one subject, virtually eliminated. Moreover, unlike subjects in the Disarmament Initiatives/Prisoner's Dilemma condition, subjects in the Disarmament Initiatives/Perceptual Dilemma condition tended to believe that the "other person" would choose disarmament on upcoming trials. Following exposure to unconditional cooperation, subjects in the Disarmament Initiatives conditions showed significant positive changes in self-rated affect, especially among subjects in a Perceptual Dilemma. There is some evidence, too, that early armament and the expectation of armament were related to prior utility estimates for arms-race outcomes, lending additional support to the external validity of the experimental interaction.

Further support for the experimental hypotheses extended beyond the 30-trial interaction. On a special "thirty-first trial," in which subjects were told that only the other person would receive feedback concerning the choices made by each participant, only 1 of 10 subjects in the Disarmament Initiatives/Perceptual Dilemma condition armed, compared with 26 of 30 subjects in the other three conditions. Subjects in the Disarmament Initiatives/Perceptual Dilemma condition also perceived the "other person" as more honest, more similar to themselves, more desirable as a friend, and more responsive than did subjects in the other three conditions. The latter set of findings is particularly dramatic for a number of reasons. First, the interaction between subjects and the alleged "other person"was brief (usually 15-20 minutes), remote (subjects never saw the "other person"), and limited (no words were ever spoken; the interaction was limited exclusively to choices of " $A$ " and " $B$ "). Second, the measures concerning social perception were broad single-item ratings, rather than more specific (and typically more sensitive) multi-item inventories. Third, the observed differences in social perception were robust enough to reach conventional levels of significance with relatively small sample sizes. Fourth, and most important of all, there was never any "other person" to begin with. Subjects judged not another person, but a series of responses based largely on their own conduct (see Snyder, 1984, on the self-fulfilling nature of social beliefs).

Mechanisms. Once initial predispositions were confirmed with an early run of arming responses by the "other person," subjects in the Status Quo conditions unwittingly forced the "other person" to continue emitting the behavior they sought to avoid. Armament by the "other person" in turn reinforced subjects' initial predispositions, leading them to believe (erroneously) with high confidence that the "other person" would arm regardless of their own behavior and that they had little control over the outcome. An "actor-observer bias" developed (Jones and Nisbett, 1971), in which subjects attributed greater choice to the "other person" than to themselves; the restriction of choice subjects perceived for themselves was strongly related to estimates of the percentage of arming responses made by the "other person," whereas estimates of the percentage of their own arming responses were not associated with perceived limitations in the "other person's" choices.

A simplified "dual-spiral" schematic of these mechanisms appears in Figure 4. Subjects in the Status Quo/Perceptual Dilemma condition, who were predisposed to avoid unilateral disarmament but did not seek unilateral armament, began the interaction by arming to defend against a perceived threat. As a consequence of the Status Quo strategy, this armament triggered reciprocal armament by the "other person," thereby increasing the original perceived threat and forcing subjects to continue arming. The left half of Figure 4 therefore represents a "defensive"spiral in which the Status Quo served to facilitate armament.

Subjects in the Status Quo/Prisoner's Dilemma condition may have acted either to avoid unilateral disarmament or to seek unilateral armament. Because the Status Quo strategy did not leave the "other person" open to systematic exploitation, however, the role of the "aggressive" spiral shown in the right half of Figure 4 was minimized. Still, in the context of a Prisoner's Dilemma it is impossible to distinguish between defensive armament and aggressive armament unless the other side disarms, providing the first side with an opportunity for unilateral armament.

In the Disarmament Initiatives conditions, subjects were presented with just such an opportunity. For 10 consecutive trials, the connection between their armament and defensive armament by the "other person" 


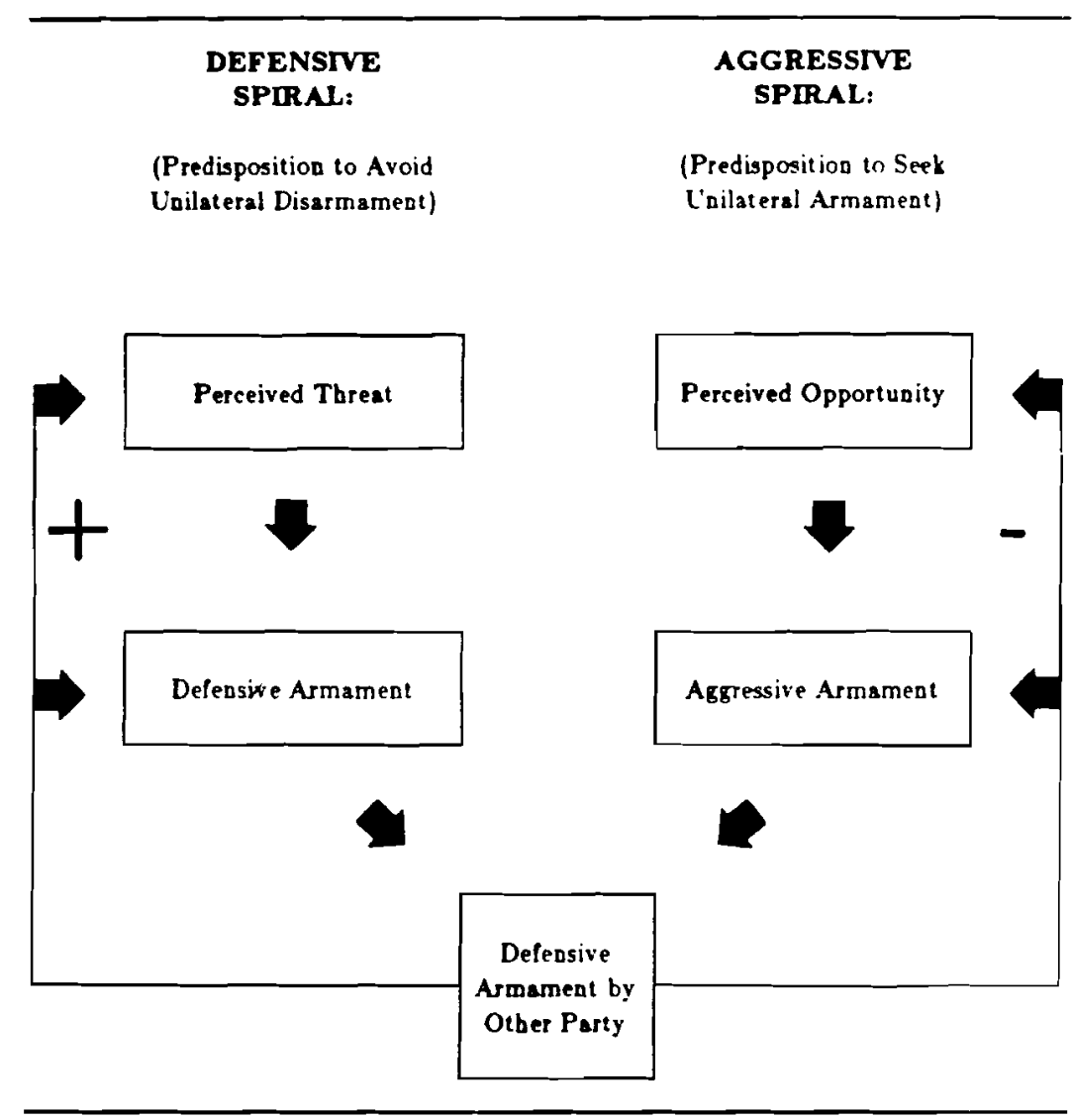

Figure 4: Dual-Spiral Schematic of the Nuclear Arms Race

was withheld. Within a Prisoner's Dilemma, subjects responded to the "other person's" disarmament initiatives by seeking unilateral armament on approximately half of the trials. ${ }^{4}$ For those subjects who sought only to avoid unilateral disarmament, the "other person's" disarmament initiatives preempted a defensive spiral and were enough to induce cooperation for the remainder of the interaction. For subjects who occasionally exploited the "other person's" disarmament initiatives, though, the introduction of matching during the final 10 trials facilitated a defensive spiral, substantially raising the total level of armament.

4. This figure corresponds well to other studies that have employed unconditional cooperation within the context of a Prisoner's Dilemma (see Rapoport et al., 1976).
Unfortunately, one property of the dual-spiral schematic is that the introduction of matching makes it impossible to tell defensive armament from aggressive armament; had the "other person" been human, he or she would have had no way of knowing that the subject's armament had become defensive. Aggressive armament is dangerous not only because it can lead to defensive reactions, but because defensive armament often leads to tenacious defensive spirals (Jervis, 1976).

In the Disarmament Initiatives/Perceptual Dilemma condition, subjects had little incentive to seek unilateral armament. Thus, when defensive armament by the "other person" was withheld, subjects were unlikely to initiate aggression and were not faced with any armament against which they had to defend. Neither the defensive nor the aggressive spiral became operational, and mutual disarmament was quickly
reached.

Limitations and Extensions. The dual-spiral schematic of the nuclear arms race is unquestionably oversimplified, as are game-theoretic models in general (Snidal, 1985; Snyder and Diesing, 1977). There are more than two spirals in the arms race, more than two participants, and certainly more than two response options. In the political arena, the true status quo does not immediately match each response in kind, the utilities are not small and fixed, the feedback is not instant and unambiguous, and verbal communication is not prohibited. The United States and the Soviet Union have interacted on far more than 30 occasions, and in fact, the individual participants have changed since the time relations began.

Some of these limitations are inherent in using a simplified gametheoretic model to simulate political phenomena, but many others suggest interesting variations for future research. For example, the computerized matching strategy could be made less responsive by interchanging tit-for-two-tats with tit-for-tat, matching on a probability basis, or programming changes and alternations in strategy (such as the inclusion of sporadic arming responses once mutual disarmament had been reached, to test for robustness). Payoffs could be allowed to vary, adding "noise" to the underlying utility configuration or actually changing the initial model (for instance, allowing the accumulation of arms within a Prisoner's Dilemma gradually to shift utilities to a Perceptual Dilemma, or allowing the reduction of arms within a Perceptual Dilemma to leave participants in a Prisoner's Dilemma). For one or both sides, postinteraction feedback could be periodically withheld, 
degraded, or distorted in a systematic or randomized manner. Declarations of desire or intent could be included, and two subjects, or groups of subjects, could interact with each other instead of a single subject interacting with a computerized strategy. Finally, although recent evidence suggests that a Perceptual Dilemma may constitute a more accurate model of the nuclear arms race than a Prisoner's Dilemma (Plous, 1985), direct utility estimates for arms-race outcomes have not yet been collected from political leaders in the Soviet Union; until these data are collected, evidence for the Soviet half of a Perceptual Dilemma will necessarily remain indirect. These are but a few of the extensions that await further laboratory and field research.

Implications. Despite their limitations, results from this experiment imply that an optimal choice of strategy in the nuclear arms race may depend critically upon the model that best approximates political reality. If either superpower seeks unilateral armament, then disarmament initiatives entail a great deal of risk. If, on the other hand, both sides truly seek mutual disarmament, then disarmament initiatives may be an individually and collectively optimal strategy.

In the absence of irrefutable evidence supporting one model over another, political decision makers must not only weigh the consequences of initiating disarmament if the United States and Soviet Union are not in a Perceptual Dilemma, but the consequences of continuing to arm if the superpowers are indeed in a Perceptual Dilemma. Political leaders are thus in a "meta-dilemma," in which their beliefs concerning armsrace utilities (that is, whether they believe the nuclear arms race is a Perceptual Dilemma, a one-sided Prisoner's Dilemma, a two-sided Prisoner's Dilemma, or some other pattern of utilities) are crossed with the empirically elusive true utilities (in other words, the configuration of utilities that actually underlies the nuclear arms race).

Because of the difficulty in assessing the other party's true utilities, the historical trend has been to err on the side of "conservatism" and assume that the other party does not desire mutual disarmament. Yet this experiment suggests a relatively safe method of ascertaining superpower utilities. If a Perceptual Dilemma underlies the nuclear arms race, then an unambiguous, unconditional, time-limited succession of disarmament initiatives will lead to mutual disarmament. ${ }^{5}$ If disarmament is

5. See Osgood's (1962) GRIT proposal for some suggestions on how disarmament initiatives might be effectively carried out. not reciprocated under these conditions, a Perceptual Dilemma cannot account for the current nuclear arms race. With present levels of redundancy in the nuclear arsenals of both superpowers, such a test would leave the strategic balance unaffected, and there is some evidence that disarmament initiatives, even if discontinued, may have a salutory effect on superpower relations (Etzioni, 1967). One thing is certain: in the absence of disarmament, each side can know only the utilities that govern mutual armament.

\section{REFERENCES}

BERES, L. R. (1982) "Myths and realities: U.S. nuclear strategy."(November) Occasional Paper 32. Muscatine, IA: The Stanley Foundation.

ECKHARDT, W. and R. K. WHITE (1967) "A test of the mirror-image hypothesis: Kennedy and Khrushchev." J. of Conflict Resolution 11: 325-332

ETZIONI, A. (1967) "The Kennedy experiment" Western Pol. Q. 20: 361-380.

FISCHHOFF, B., P. SLOVIC and S. LICHTENSTEIN (1977) "Knowing with certainty: the appropriateness of extreme confidence." J. of Experimental Psychology: Human Perception and Performance 3: 552-564.

GAMSON, W. A. and A. MODIGLIANI (1971) Untangling the Cold War: A Strategy for Testing Rival Theories. Boston, MA: Little, Brown.

GAYLOR, N. (1982) "How to break the momentum of the nuclear arms race."New York Times Magazine (April 25): 48, 49, 86, 88.

HOGAN, J. L., R. H. FISHER and B. J. MORRISON (1973) "Accuracy of prediction and cooperative game behavior." Perceptual and Motor Skills 37: 391-398.

HOLSTI, O. R., R. A. BRODY and R. C. NORTH (1964) "Measuring affect and action in international reaction models: empirical materials from the 1962 Cuban Missile Crisis." J. of Peace Research 1: 170-190.

JERVIS, R. (1976) Perception and Misperception in International Politics. Princeton, NJ: Princeton Univ. Press.

JONES, E. E. and R. E. NISBETT (1971) "The actor and the observer: divergent perceptions of the causes of behavior," in E. E. Jones et al. (eds.) Attribution: Perceiving the Causes of Behavior. New York: General Learning Corporation.

KELLEY, H. H. and A. J. STAHELSKI (1970) "Social interaction basis of cooperators" and competitors' beliefs about others." J. of Personality and Social Psychology 16 66-91.

KUHLMAN, D. M. and D. L. WIMBERLEY (1976) "Expectations of choice behavio held by cooperators, competitors, and individualists across four classes of experimental game." J of Personality and Social Psychology 34: 69-81.

LA ROCQUE, G. R. (1981) “U.S. nuclear weapons accidents: danger in our midst." The Defense Monitor 10,5: 1-12.

LICHTENSTEIN, S., FISCHHOFF, B. and L. D. PHILLIPS (1982) "Calibration of probabilities: the state of the art to 1980," in D. Kahneman, P. Slovic, and A. Tversky 
(eds.) Judgment under Uncertainty: Heuristics and Biases. New York: Cambridge Univ. Press.

LINDSKOLD, S. (1978) "Trust development, the GRIT proposal, and the effects of conciliatory acts on conflict and cooperation." Psych. Bulletin 85: 772-793.

MAKI, J. E. and C. G. McCLINTOCK (1983) "The accuracy of social value prediction: actor and observer influences." J. of Personality and Social Psychology 45: 829-838.

MESSE, L. A. and J. M. SIVACEK (1979) "Predictions of others' responses in a mixed-motive game: self-justification or false consensus?"J. of Personality and Social Psychology 37: 602-607.

MILLER, D. T. and J. G. HOLMES (1975) "The role of situational restrictiveness on selffulfilling prophesies: a theoretical and empirical extension of Kelley and Stahelski's triangle hypothesis." J. of Personality and Social Psychology 31: 661-673.

MYRDAL, A. (1982) The Game of Disarmament: How the United States and Russia Run the Arms Race. New York: Pantheon.

NUNN, S. and J. W. WARNER (1984) "Reducing the risk of nuclear war." The Washington Q. 7, 2: 2-7.

OSGOOD, C. E. (1962) An Alternative to War or Surrender. Urbana: Univ. of Illinois Press.

PERRY, W. (1983) “Measures to reduce the risk of nuclear war," in J. W. Lewis and C. D. Blacker (eds.) "Next steps in the creation of an accidental nuclear war prevention center. Special Report of the Center for International Security and Arms Control, Stanford University.

PILISUK, M. (1984) "Experimenting with the arms race." J. of Conflict Resolution 28: 296-315.

PILISUK, M., P. POTTER, A. RAPOPORT and J. A. WINTER (1965) "War hawks and peace doves: alternative resolutions of experimental conflicts." J. of Conflict Resolution 9: 491-508.

PILISUK, M. and A. RAPOPORT (1964) "Stepwise disarmament and sudden destruction in a two-person game: a research tool." J. of Conflict Resolution 8: 36-49.

PILISUK, M. and P. SKOLNICK (1968) "Inducing trust: a test of the Osgood proposal." J. of Personality and Social Psychology 8: 121-133.

PLOUS, S. (1985) "Perceptual illusions and military realities: a social-psychological analysis of the nuclear arms race." J. of Conflict Resolution 29: 363-389.

RAPOPORT, A., M. J. GUYER, and D. G. GORDON (1976) The $2 \times 2$ Game. Ann Arbor: Univ. of Michigan Press.

RUSSETT, B. (1983) The Prisoners of Insecurity: Nuclear Deterrence, the Arms Race, and Arms Control. San Francisco: W. H. Freeman.

SIVARD, R. (1983) World Military and Social Expenditures. Leesburg, VA: World Priorities Incorporated

SNIDAL, D. (1985) "Coordination versus Prisoners' Dilemma: implications for international cooperation and regimes." Amer. Pol. Sci. Rev. 79: 923-942.

SNYDER, G. H. and P. DIESING (1977) Conflict among Nations: Bargaining, Decision Making, and System Structure in International Crises. Princeton, NJ: Princeton Univ Press.

SNYDER, M. (1984) "When belief creates reality." Advances in Experimental Social Psychology 18: 247-305. 